\title{
LA IRRACIONALIDAD COMO LAVA ARDIENTE O RUIDOSA CONVERSACIÓN
}

\section{The irrationality as burning lava or noisily conversation}

Héctor Ponce*

\section{Resumen}

Richard Rorty subraya las metáforas de Freud sobre consensos y disensos entre distintos grupos de creencias, en lugar interpretar al inconsciente sólo como un magma irracional de tendencias salvajes y al yo como plenamente integrado. Rorty prefiere al Freud que comprendió a la mente como formada por constelaciones de creencias, deseos y disposiciones no plenamente integradas, y presenta un inconsciente ingenioso, pasional y articulado en razones. Además se mostrará la relevancia de la subjetividad del psicoanalista en la terapia. El objetivo del texto es una evaluación personal, las fuentes son bibliográficas y las conclusiones son dos: 1) es preferible la versión del lingüístico inconsciente (integrado a creencias, deseos y acciones); y 2) la nulidad de la terapia neutral.

Palabras claves: Psicoanálisis, epistemilogía, metodología, terapia freudiana y espistolario.

\begin{abstract}
Epistemology and psychoanalysis methodology are discussed, as well as how to ethically evaluate the recent findings of Freud's private correspondence, where the recovery of some of his patients he claims to have cured is disputed.

The aim is a personal evaluation, the sources are bibliographical, and the conclusions are three in number. 1) In epistemology, psychoanalysis is found within human sciences and Freud created a valuable theory of the mind - that one has several conflicted desires - that allows for new routes to retrospection. 2) In methodology, psychoanalysis is enriched if, instead of appealing to the "laws of the unconscious," it is inspired by hermeneutics. 3) In ethics, Freud was not truthful to present as completed processes several patients who did not therapeutically get better, and the psychoanalytic community has not spoken up accordingly.
\end{abstract}

Keywords: Psychoanalysis, epistemology, methodology, Freudian therapy and epistolary.

\footnotetext{
* Docente de Filosofía en la Facultad de Psicología de la Universidad Femenina del Sagrado Corazón (UNIFÉ).heaponce@yahoo.es
} 
Lo nuevo en la concepción freudiana del inconsciente es su afirmación de que nuestro yo inconsciente no es un animal mudo, hosco y tambaleante, sino más bien el par intelectual de nuestro sí mismo consciente, el posible interlocutor de este sí mismo. Freud y la reflexión moral. Richard Rorty (1993. p. 209).

\section{INCONSCIENTE INGENIOSO}

A lo largo de la obra de Freud hay dos marcos teóricos acerca de la irracionalidad; uno continúa el mundo oscuro de las motivaciones inconscientes, otro se diferencia de los textos canónicos que han tratado el tema de lo irracional. El inconsciente no es, como creyeron algunos filósofos, ni una hipóstasis metafísica ni de un elemento adicional y periférico de la conciencia ${ }^{1}$. Freud rechazó que el inconsciente sea un tonel en que yacen amontonados y sepultados nuestros recuerdos, y lo consideró activo, presente día y noche cuando soñamos, cometemos lapsus o se nos ocurre un chiste ${ }^{2}$. no sólo se forja ahí lo más bajo y vil del ser humano, sino también las agudas ocurrencias ${ }^{3}$.

Era la diferencia entre el "inconsciente descriptivo" y el "inconsciente dinámico", y a pesar de que Freud renegaba del tono metafísico, él mismo utilizó ese lenguaje cuando señalaba que el inconsciente no podía ser conocido por sí mismo, el inconsciente era conocido sólo por medio de sus manifestaciones, presentando así al inconsciente como Platón presentó a la idea del Bien y Kant a la cosa en sí ${ }^{4}$.

Al ser incognoscible, el inconsciente llevaba a Freud hacia la "psicología de las profundidades" (Freud, 1915, Vol. II, p. 2065) y suscribió una idea de Groddeck: aquello que llamamos nuestro yo se conduce en la vida muchas veces de manera pasiva $\mathrm{y}$, en vez de vivir, somos vividos por fuerzas que desconocemos. Nietzsche nombró a estos instintos "ello"5 . Es así como Freud construyó una teoría de la mente en que el yo era la percepción y el ello era la caldera en ebullición, la lava ardiente de las pulsiones o instintos.

Esta teoría de la mente, sin embargo, no es nueva, continua la herencia de la cultura griega, pues el yo representaba a la razón y el ello a las ariscas pasiones, según Platón. Al leer en El yo y el ello ("El yo representa lo que pudiéramos llamar la razón o la reflexión, opuestamente al ello, que contiene las

1. "Los filósofos se han ocupado desde luego repetidamente del problema de lo inconsciente, pero adoptando en general [...] una de las dos posiciones siguientes: o han considerado lo inconsciente como algo místico, inaprensible e indemostrable, cuya relación con lo anímico permanecía en la oscuridad, o han identificado lo psíquico con lo consciente, deduciendo luego de esta definición que algo que era inconsciente no podía ser psíquico, ni, por tanto, objeto de la Psicología" (Freud, 1913, pp. 881-882).

2. Paul-Laurent Assoun a este respecto dice: "La revolución psicoanalítica no radica en la revelación del inconsciente; Freud dice explícitamente: 'Los filósofos se han ocupado desde luego repetidamente del problema de lo inconsciente.' No se trata, pues, de introducir una materia nueva; el inconsciente es, ya un capítulo importante del discurso filosófico. En cambio, la teoría analítica tiene el efecto profundamente original de recusar dos tesis filosóficas opuestas y complementarias: por una parte, el conciencialismo, que excluye al inconsciente de la vida psíquica; por otra parte, el trascendentalismo del Inconsciente (aquí las mayúsculas tiene un sentido) que convierte al inconsciente en entidad metafísica. Este doble efecto revelador ataca, pues, una tesis única: El divorcio del inconsciente y de lo psíquico" (1982, p. 39).

3. En El yo y el ello, Freud señala que "no sólo lo más bajo, sino también lo más elevado, puede permanecer inconsciente" (Freud, 1923,p. 1219). El texto continúa así: "Acostumbrados a no abandonar nunca el punto de vista de una valoración ética y social, no nos sorprende oír que la actividad de las pasiones más bajas se desarrolla en lo inconsciente, y esperamos que las funciones anímicas encuentren tanto más seguramente acceso a la conciencia cuanto más elevado sea el lugar que ocupen en dicha escala de valores. Pero la experiencia psicoanalítica nos demuestra que la esperanza es infundada. Por un lado tenemos pruebas de que incluso una labor intelectual sutil y complicada, que exige, en general, intensa reflexión, puede ser también realizada preconscientemente, sin llegar a la conciencia. Este fenómeno se da, por ejemplo, durante el estado de reposo y se manifiesta en que el sujeto despierta sabiendo la solución de un problema matemático o de otro género cualquiera, vanamente buscada durante el día anterior" (1923,p. 1219).

4. "Del mismo modo -dijo Freud- que Kant nos invitó [...] a no considerar nuestra percepción idéntica a lo percibido incognoscible, nos invita el psicoanálisis a no confundir la percepción de la conciencia con los procesos psíquicos inconscientes" (Freud, 1915, p. 2064).

5. La nota a pie de página de El yo y el ello dice: "Groddeck sigue el ejemplo de Nietzsche, el cual usa frecuentemente este término como expresión de lo que en nuestro ser hay de impersonal" (Freud, 1923, p. 1218). En otro texto, Freud explicita la influencia que tiene de Nietzsche: "Apoyándonos en el léxico nietzscheano y siguiendo una propuesta de G. Groddeck, lo llamaremos en adelante el ello. Este pronombre personal parece expresar el carácter capital de tal provincia del alma, o sea su calidad de ajena al yo" (Freud, 1932, p. 820). 
pasiones" (1923, p. 1218), uno ve que Freud no está muy alejado del Fedro de Platón en la medida en que ambos presuponen que la mente tiene un centro privilegiado, un ápice de conciencia pura, rodeado de un mar de salvajes pasiones. Esto se ve cuando Platón indicaba que nuestra identidad era como una carroza, con sus caballos y aurigas, en movimiento.

Dividimos toda alma en tres partes; a dos de ellas, dimos forma de caballo. Y a la tercera, de auriga. (...) De esos dos caballos, uno es bueno; el otro, no. (...) El que de ellos tiene mejor condición, es de figura recta y erguida, tiene el cuello alto, ligeramente curvo, el color blanco y los ojos negros, es amante de la gloria con moderación y de la opinión verdadera, y, sin necesidad de golpes, se deja conducir por una orden simplemente, o por una palabra. El otro, el contrario, es contrahecho, pesado, (...) de cuello robusto y corto, frente achatada, de color negro y ojos grises, sanguíneo, compañero del exceso y de la soberbia, de orejas peludas, sordo, y obedece a duras penas a un látigo con pinchos. Así, pues, cuando el auriga, contemplando la visión amorosa y habiendo calentado toda su alma con esta percepción, está casi lleno del cosquilleo y los pinchazos del deseo, el caballo que le es dócil, dominado entonces, como siempre, por el respeto, se retiene a sí mismo de echarse sobre el amado; pero el otro, sin preocuparse ya ni de los pinchos del auriga ni del látigo, se lanza a saltos violentos, dando todo el trabajo imaginable a su compañero de yugo y al auriga y forzándolos a ir hacia el amado y a recordarle las delicias del amor. (Platón. Fedro 253e, 254b).

La difícil y tensa relación que existe entre un auriga que pretende dirigir y algunos caballos que ciegamente tiran de la carroza y a veces terminan dirigiendo, es análoga a la relación que, según Freud, tendría nuestro yo y nuestras bestiales pasiones, una relación marcada no por el diálogo sino dividida por un abismo entre la razón y las pasiones. Veamos qué escribió Freud sobre el yo.

Podemos, pues, compararlo, en su relación con el ello, al jinete que rige y refrena la fuerza de su cabalgadura, superior a la suya, con la diferencia de que el jinete lleva esto a cabo con sus propias energías, y el yo, con energías prestadas. Pero así como el jinete se ve obligado alguna vez a dejarse conducir adonde su cabalgadura quiere, también el yo se nos muestra forzado en ocasiones a transformar en acción la voluntad del ello, como si fuera la suya propia (Freud, 1923, p. 1219) ${ }^{6}$.

Freud simplemente resulta una extensión de la genial metáfora de Platón cuando identifica a las pulsiones con ese reservorio salvaje e incoherente en que vivirían como "astutas serpientes e inocentes palomas" . En varios pasajes, cuando Freud interpreta al ello como irracionalidad absoluta, no dice nada distinto a lo que sus antecesores habían dicho sobre las pasiones, pues casi todos las denunciaban como caóticas. Así leemos otro pasaje en que, al igual que Platón, Freud despoja de coherencia a las pasiones e indica que el ello es un magma irracional.

[El ello] es la parte oscura e inaccesible de nuestra personalidad: lo poco que de él sabemos lo hemos averiguado mediante el estudio de la elaboración onírica y de la producción de síntomas neuróticos, y en su mayor parte tiene carácter negativo, no pudiendo ser descrito sino como antitético al yo. [...] Carece de organización, no genera una voluntad conjunta [...], en él no son válidas las leyes lógicas del pensamiento, y menos que ninguna, el principio de la contradicción. Impulsos

6. La misma situación se ve en otro pasaje de Freud: "el ello es totalmente amoral; el yo se esfuerza en ser moral, y el superyó puede ser 'hipermoral"” Freud, op. cit., p. 1231. En palabras de Rorty: "Si se interpreta el dictum de Freud de que el yo no es dueño de su propia casa en el sentido de que a menudo actuamos de formas que no podrían haberse predicho sobre la base de nuestras creencias y deseos conocidos por introspección, Freud simplemente estaría reiterando un lugar común del pensamiento griego.” (Rorty, 1991, p. 204).

7. La referencia es al pasaje bíblico de Mateo 10:16. "Mirad que yo os envío como ovejas en medio de lobos. Sed, pues, prudentes como las serpientes y sencillos como las palomas". [Biblia] Biblia de Jerusalén. Edición española dirigida por José Ángel Ubieta. Bilbao: Editorial Española Desclée de Brouwer, 1998. 
contradictorios coexisten en él [...]. No hay en el ello nada equivalente a la negación y (...) no hay nada que corresponda a la representación del tiempo; no hay reconocimiento de un decurso temporal. [...] No conoce valoración alguna: no conoce el Bien ni el Mal, ni moral ninguna. [...] Todo lo que el ello contiene son cargas de instinto que demandan derivación. [...] Sirviéndonos del léxico corriente, podemos decirque el yo representa en la vida anímica la razón y la reflexión, mientras que el ello representa las pasiones indómitas (Freud, 1932, Vol. III, pp. 821-822) .

Presentado de esta manera, en el grado máximo de incoherencia, el ello es inexplicable y sus acciones injustificables, pues las creencias y los motivos inconscientes carecerían de cualquier tipo de organización, llevando a Freud a paradojas y sofismas: "Los contrarios se encuentran muy próximos unos de otros en la asociación, e incluso llegan a confundirse" (Freud. 1917, p. 171).

Si Freud se hubiese quedado en esta lectura, no hubiese dicho nada novedoso; hay, sin embargo, en su obra una manera de explicar ese caldero que bulle caóticamente, y sería mediante las coordenadas que ofrecen la asociación y condensación de las creencias y del fluir del inconsciente. Otros serán, desde luego, los problemas que enfrentan tales conceptos -que Lacan reinterpretó como el trabajo de la metáfora y la metonimia-. Pero detengámonos en la interpretación que hace Richard Rorty de Freud

El psicoanálisis como una reflexión sobre la irracionalidad (Cavell, 2000, p. 21), no necesita crear leyes universales de asociación y condensación, le bastan un analizado y un analista que forjen interpretaciones empáticas sobre la retrospección y prospección del paciente. Siguiendo la deconstrucción del sujeto trascendental realizada por Heidegger, y antes por Marx, Nietzsche y Kierkegaard, Rorty suscribiría el pasaje "Las servidumbres del yo" escrito por Freud: "Se nos muestra el yo como una pobre cosa sometida a tres distintas servidumbres y amenazas por tres diversos peligros [:] el mundo exterior, de la libido y del rigor del superyó" (Freud, 1923, p. 2726) ${ }^{9}$. Rorty no busca robustecer al yo trascendental, sino desinflar las tinieblas del inconsciente. Rorty no busca que el yo se alce por encima de las contingencias (no cree que eso sea posible), sino expandir al yo, ello y superyó. Sin creer que son las únicas causas, Rorty suscribiría las razones ofrecidas por Freud sobre la religión: "las necesidades religiosas [...] se derivan del desamparo infantil y de la nostalgia por el padre [y] por la angustia ante la omnipotencia del destino" (Freud, 1923 , p. 3022). Rorty busca desenredar a Freud: no mentalizar lo biológico, no biologizar lo mental (Cfr. Cavell, 2000, p. 99). Para Rorty es básico asumir que el cerebro se estudia con la descripción nomológico y causal, mientras la mente se ilumina con la descripción narrativa y teleológica.

El carácter narrativo de lo mental está íntimamente conectado con el descubrimiento crucial de Freud de que contar y volver a contar nuestras historias nos puede liberar en cierta manera del pasado y al mismo tiempo dar mayor armonía a los propósitos, intenciones y acciones actuales, así como a sus consecuencias. (Cavell, 2000, p. 150).

La dicotomía entre razón y pasión anidada en la mente es modificada por la topografía del yo, superyó y ello entrelazados y compartiendo criterios emocionales y coherentes. Rorty rescata una metáfora freudiana: "el yo no es dueño de su propia casa". Tal metáfora apunta a que a veces, y quizás más de lo que esperábamos, realizamos acciones irracionales sobre las bases de las creencias y deseos del yo, sobre la base de algunas

8. Freud, 1932, Vol. III, pp. 821-822. "Tampoco debemos suponer demasiado rígida la diferencia entre el yo y el ello, olvidando que el yo no es sino una parte del ello, especialmente diferenciada. Los sucesos del yo parecen, al principio, no ser susceptibles de constituir una herencia, pero cuando se repiten con frecuencia e intensidad suficientes en individuos de generaciones sucesivas, se transforman, por decirlo así, en sucesos del ello, cuyas impresiones quedan conservadas hereditariamente. De este modo abriga el ello en sí innumerables existencias del yo, y cuando el yo extrae del ello su superyó, no hace, quizá, sino resucitar antiguas formas del yo.” (Freud, 1923, p. 1219).

9. Freud escribió: "El filósofo Kant dijo [...] que nada le probaba tan convincentemente la grandeza de Dios como el firmamento estrellado y nuestra conciencia moral. Los astros son ciertamente magníficos; peor lo que hace a la conciencia moral, Dios ha llevado a cabo una labor desigual y negligente, pues una gran mayoría de los hombres no ha recibido sino muy poca [...]”. (Freud, 1932, p. 3135). 
de nuestras creencias y nuestros deseos conocidos por introspección (Rorty, 1991, p. 204), pero esas mismas acciones adquieren sentido desde otro grupo de creencias y deseos. Aquí tiene sentido proponer dos tipos de inconsciente: el inconsciente coprolálico y otro al que Rorty llama "inconsciente ingenioso". El inconsciente coprolálico equivaldría a una enorme masa de energías instintivas (o pulsionales) incapaces de expresarse; sería una reserva de libido para la cual es irrelevante la congruencia y en la que reina la irracionalidad absoluta. El inconsciente ingenioso, en cambio, es perspicaz y alejado de la mística y de lo misterioso, es el que equivale a sistemas de creencias, deseos y acciones articulados entre sí, serían constelaciones de ideas, propósitos y actividades entre las cuales podría haber, al menos como condición preliminar, posibles diálogos, traducciones, pues serían constelaciones dotadas de tanta congruencia interna como las creencias y deseos conscientes, y, en lugar de sólo disenso, podrían entretejer "sentido" y consenso con las creencias de las otras instancias mentales.

Siguiendo las pistas del segundo sentido, un deseo oculto a nuestra consciencia tendría una intención relacionada con una amplia gama de creencias, deseos y acciones junto con los cuales conformaría una urdimbre. De asumir el "inconsciente coprolálico", sólo se tiene otro nombre para designar negativamente a las pasiones -el sentido que la tradición platónica les dio como parte inferior de nuestra identidad-, pero, como sostiene Rorty, nuestros modos de retrospección son distintos gracias a Freud (Rorty, 1993, p. 209). Un inconsciente ingenioso es comprendido mediante las intenciones que justifican nuestras acciones, acciones que pueden ir desde tramar una gran venganza hasta un insignificante lapsus. Desde que se atribuyen al ello, yo y superyó creencias justificadas y coherentes al interior de sí mismos, nuestro vocabulario introspectivo se asemeja al modelo de las relaciones intersubjetivas, y las tres instancias se representan como agentes relativamente autónomos (el superyó puede comportarse sádicamente contra el yo). Y nuestras acciones irracionales adquieren sentido al cambiar el punto de observación: las acciones del ello parecerán irracionales al yo, pero vistas desde el ello cobran sentido.

Donald Davidson es uno de los autores de los que Rorty es heredero, y fue quien en la filosofía de corte anglosajona presentó la idea de que la mente, lejos de ser una entidad inalterable, podía comprenderse también como agrupaciones de distintos sistemas de creencias, cada cual con propósitos, fines y metas particulares.

En primer lugar, la mente contiene varias estructuras semi independientes que se caracterizan por atributos mentales como pensamientos, deseos y recuerdos. En segundo lugar, las partes de la mente son como personas en aspectos muy importantes, no sólo en que tienen (o consisten en) creencias, anhelos y otros rasgos psicológicos, sino en que estos factores pueden combinarse, como en la acción intencional, para causar otros sucesos en la mente o fuera de ella. En tercer lugar, algunas de las disposiciones, actitudes y sucesos que caracterizan las diversas subestructuras de la mente deben observarse según el modelo de las disposiciones y fuerzas psíquicas cuando afectan otras subestructuras de la mente o son afectadas por éstas. (Davidson, 1982, pp. 290-291).

Ahora resulta ininteligible definir al ello como el magma de pulsiones prelingüística y carente de organización, y permite ver que el aporte original de Freud es permitirnos reflexionar sobre nosotros, como cuando enfrentamos, dialécticamente, descripciones opuestas, por ejemplo, en torno de la madre como una seductora furtiva o como un ser martirizado.

Si nuestros propósitos son comprender nuestra identidad, de poco ayudan las metáforas hidráulicas de Freud en su versión de catexias, fuerzas y torrentes libidinales, pues frente a ese poco sofisticado, pero colosal sistema de fontanería y desaguadero poco o nada se puede evitar (salvo construir represas y cloacas para el quantum pulsional), y lo mismo ocurre si alguien intenta comprender, pongamos por caso, las motivaciones que lo llevaron a un músico a tocar tal o cual instrumento y busca una respuesta en el tipo de sangre que se posee o las secreciones del sistema endocrino. Cuando lo inconsciente, más bien, pasa al terreno de la comprensión lingüística, se acerca significativamente a las interrogantes que nos plantea un verso enigmático y le atribuimos una intención que queremos descubrir. El psicoanalista obraría como un crítico de arte que interpreta "mostrando una cosa como 
otra", llevando la observación a algún detalle. "Las perspicaces observaciones del analista en ocasiones puede ser más una cuestión de hablar metafóricamente que de decir la verdad literal" (Cavell, 2000, p. 159)

Esta aplicación -opina Rorty- rompe el vínculo entre la distinción platónica entre razón y pasión y la distinción consciente e inconsciente. Sustituye así la tradicional imagen de un 'intelecto' que lucha con una multitud de brutos 'irracionales' por una imagen de complejas transacciones entre dos o más 'intelectos'. (...) Un inconsciente ingenioso es necesariamente un inconsciente lingüístico. Además, si "racional" significa "capaz de urdir redes complejas de creencias, dotadas de coherencia interna" en vez de "capaz de contemplar la realidad tal cual es", entonces un inconsciente ingenioso es también un inconsciente racional -es decir- que, al igual que la consciencia, no puede tolerar las incongruencias. Tenemos que distinguir así entre el inconsciente como "los estratos más profundos de nuestra mente, compuestos de impulsos instintivos", estratos que no conocen "nada negativo, ni negación", en los cuales "coinciden los contrarios", y el inconsciente como el interlocutor sensible y excéntrico de la trastienda que nos proporciona nuestros mejores versos. (Rorty. “1991, p. 210).

La tradición platónico-kantiana interpretó a cada persona como la tensión entre la razón y sus pasiones irracionales, poseedora de un yo traslúcido y plenamente integrado, mientras Freud resignificó cómo reflexionamos sobre nuestra identidad, dándonos estrategias de diálogos entre las tres instancias que conforman nuestra mente. Puntualmente, el ello sería la instancia que busca satisfacer deseos inmediatos y compulsivos; el superyó aquella que busca lo normativo y punitivo; y el yo estaría encargado de los planes y deseos a largo plazo. A cada una de estas tres constelaciones se les puede ver como grupos de creencias que guardan coherencia entre sí y a las cuales les corresponderían la realización de distintas acciones. Se les puede ver, también, como identidades coherentes entre creencias, deseos y acciones, pues la mente es interpretada desde un ángulo muy distinto del planteado por Platón. Gianni Vattimo, desde la filosofía continental, que "la [mente] es el campo donde luchan distintas 'partes' del yo, sin que sea nunca posible decir cuál de estos yoes distintos es el auténtico" (2004, p. $91)^{10}$.

Lo inconsciente dinámico no es algo sustantivado o hipostasiado por medio del cual se manifestarían algunos efectos, sino que dicho inconsciente dinámico es las manifestaciones de sus efectos: sueños, lapsus, síntomas neuróticos, etc. Un ejemplo de Ryle puede aclarar la idea:

A un extranjero que visita Oxford o Cambridge por primeravez, se le muestran los colleges, bibliotecas, campos de deportes, museos, departamentos científicos y oficinas administrativas. Pero luego pregunta: 'Dónde está la Universidad. He visto dónde viven los miembros de los colleges, dónde trabaja el Registrados (Registrar), dónde hacen experimentos los científicos, pero aún no he visto la Universidad (...).' Se le tiene que explicar, entonces, que la Universidad no es otra institución paralela o una especie de contrapartida de los colleges, laboratorios y oficinas. La Universidad es la manera en que todo lo que ha visto se encuentra organizado. Cuando se ven sus edificios y se comprende su coordinación, puede decirse que se ha visto la Universidad. (Ryle. 1967, p.19).

De manera similar, lo inconsciente es otra manera de nombrar a los sueños, lapsus y síntomas, es decir, no sólo son intenciones sin manifestaciones en el comportamiento. Sin embargo, algunas corrientes psicoanalíticas asumen que la pulsión es el núcleo esencial que irradia energía a la manera de una entidad que sólo se manifiesta a través de sus efectos. Así lo piensa en la actualidad, por ejemplo, André Green a propósito de la pulsión: "La pulsión no es consciente ni inconsciente [...] y es sólo cognoscible por sus representantes." (Green. 1998-1999: 6, p. 328)11. Asimismo, Otto Kernberg: "En la concepción freudiana

10. Vattimo usa la palabra 'yo' en el lugar en el que se ha colocado la palabra 'mente'. El cambio se hace para evitar cualquier equívoco, pues en este ensayo se postula que uno de los 'yoes' es parte de la 'mente'.

11. Green continúa en su interpretación de Freud diciendo: "Freud afirma que en el Ello no hay representaciones ni contenido alguno." Ibíd., p. 329. 
[a las pulsiones] sólo podemos conocerlas a través de sus representantes psíquicos: las ideas y los afectos" (Kernberg. 1994. pp. 16-17) ${ }^{12}$. A diferencia de Green y Kernberg, el neopragmatismo de Rorty no define al inconsciente como una entidad hipostasiada y más bien sugiere identificar directamente al inconsciente con los sueños, los lapsus y los chistes. Si esta tarea no ha sido llevada a cabo es, por lo menos, por dos razones: primero, porque el concepto "inconsciente" empleado confusamente sirve de panacea y, segundo, porque -como lo ha expresado Wittgenstein- "estamos dispuestos a creer un montón de cosas porque son misteriosas" (Wittgenstein, 1992, p. 30).

En la línea de Wittgenstein, los sueños, los actos fallidos, los síntomas y otras acciones (los pretendidos representantes del inconsciente pulsional) son el inconsciente mismo sin misticismo. Cuando el psicoanálisis cree en las pulsiones, lo hace creyendo que ha encontrado la fuente original de los sueños, actos fallidos, síntomas, etc.; pero podemos hacer a un lado a la pulsión entendida como fuerza inicial y esencial de la psique: "no hay una consoladora distinción entre un ordo essendi fijo y un ordo cognoscendi histórico y transitorio" (Rorty, 2000, p. 171).

El psicoanálisis puede postular un inconsciente dinámico como el anidamiento y el equivalente de $n$-cotomía ${ }^{13}$ de identidades; sin embargo, se limita el postulado a tres voluntades de la mente. El ello, yo y superyó tienen sueños, actos fallidos y síntomas.
(Nietzsche hubiese interpretado al inconsciente dinámico como una pluralidad de yoes con una dirección para $\operatorname{actuar}^{14}$ ). Postular el inconsciente dinámico permite explicar, por ejemplo, que muchos recuerdos persisten en las personas pero no de manera pasiva sino más bien de forma activa ${ }^{15}$. Precisamente, el leitmotiv psicoanalítico es que el paciente "padecería de reminiscencias" olvidadas (Cfr. Freud, 1895, VOL II, p. 27). Este oxímoron se aclara al tener en cuenta que el recuerdo continuaría obrando pero bajo la forma de un acto compulsivo ${ }^{16}$.

Un pasaje de inicio de Conversación en la Catedral de Vargas Llosa retrata magistralmente las cuestiones aquí discutidas. A parte de las microexpresiones, Ambrosio, ex-chofer de la familia de Santiago Zavala, reacciona aparentemente sólo con instintos salvajes y sin sentido, pero la novela irá revelando las razones de Ambrosio para detestar a Santiago.

[Ambrosio] guarda el billete sin mirarlo y sale junto a Santiago. Un río de camiones, ómnibus y automóviles atraviesa el Puente del Ejército, ¿qué cara pondría si?, en la neblina los montones terrosos de casuchas de Fray Martín de Porres, ¿se echaría a correr?, se divisan como en sueños. Mira al zambo a los ojos y él lo mira:

-Si me mataban a mi perro, creo que yo los mataba a ustedes $-\mathrm{y}$ trata de sonreír.

No,Zavalita, no te reconoce. Escucha con atención y su mirada es turbia, distante y respetuosa.

12. "Freud diferenció claramente las pulsiones de los instintos. Consideraba las pulsiones como de nivel superior; eran fuentes de motivación constante, y no intermitente. Los instintos, por otra parte, eran biológicos, heredados e intermitentes, en cuanto los activaba la estimulación psicológica y/o ambiental. La libido es una pulsión; el hambre es un instinto. En la concepción freudiana, las pulsiones son los límites entre lo físico y lo mental, como procesos físicos con raíces en la biología; él sostenía (...) que sólo podemos conocerlas a través de sus representantes psíquicos: las ideas y los afectos" (Kernberg, op. cit., p. 16-17).

13. La expresión es de Quine ([1962]1969, p. 29).

14. La frase literal de Nietzsche dice: "El alma sólo es una palabra para una partícula del cuerpo. El cuerpo es un gran sistema de razón, una multiplicidad con una sola dirección, una guerra y una paz, un rebaño y un pastor. (...) Dices "yo" y te sientes orgulloso de esta palabra." (Nietzsche, 2001, p. 31). Parafraseando también a Bertrand Russell se puede decir que la mente es un enjambre de yoes que buscan acción. "Creo que el universo es un enjambre de puntos y saltos, sin unidad, sin continuidad, sin coherencia ni orden, ni ninguna de las otras propiedades que las institutrices amas". (Russell, 1983, p. 85).

15. Freud estaba entendiendo a la represión como la falta de traducción verbal de ciertos materiales que no acceden a la conciencia. La razón de esa carencia sería la producción de displacer por parte de dicha traducción, y todo ocurre como si ese displacer perturbara el pensamiento.

16. La división de la mente se hace plausible también al asumir que no es el médico sino el paciente mismo quien es el poseedor del conocimiento sobre el origen de la enfermedad: "sólo que [una parte de] éste ignora lo que sabe." (Rey de Castro. Marzo, 1995.p. 11). 
Además de envejecer se habría embrutecido también. Piensa: jodido, también.

- ¿Se lo recogieron esta mañana al lanudito? - un brillo inesperado estalla un instante en sus ojos-. Sería el negro Céspedes, a ése no le importa nada. Se mete a los jardines, rompe las cadenas, cualquier cosa con tal de ganarse su sol.

Están al pie de la escalera que sube a Alfonso Ugarte; el Batuque se revuelca en la tierra y ladra al cielo ceniza.

- ¿Ambrosio? - sonríe, vacila, sonríe-. ¿No eres Ambrosio?

No se echa a correr, no dice nada. Mira con expresión anonadada y estúpida y, de pronto, hay en sus ojos una especie de vértigo.

- ¿Te has olvidado de mí? - vacila, sonríe, vacila - . Soy Santiago, el hijo de don Fermín.

Las manazas se alzan, ¿el niño Santiago, don?, se inmovilizan como dudando entre estrangularlo y abrazarlo, ¿el hijo de don Fermín? Tiene la voz rota de sorpresa o emoción y parpadea, cegado. Claro, hombre ¿no lo reconocía? (Vargas Llosa, 1969, pp. 27-28).

\section{INTERSUBJETIVIDAD}

En la práctica, los terapeutas y los pacientes crean interpretaciones que permiten reconocer qué calidad de lazos hubo en el pasado con personas significativas. Pero hay más. Es plausible que la relación entre el terapeuta y quien lo consulta -conocida como relación de transferencia- sea la causa de la atenuación de los malestares del paciente, sencillamente porque la identidad es influenciable:
Las relaciones a lo largo de la vida -con amigos o parientes, por ejemplo, o en psicoterapiaremodelan constantemente el modelo operativo de las relaciones. Un desequilibrio de un momento determinado puede corregirse más tarde; es un proceso continuo que se desarrolla a lo largo de la vida. (Stern, 1987, p. 30).

La transferencia señala que si todo adulto tiene como uno de los modelos centrales para sus relaciones interpersonales la relación primera que tuvo con sus padres, entonces el análisis tratará de revivir emocionalmente aquella primera relación del niño con sus progenitores con el fin de conocer ese primer modelo. El psicoanalista Etchegoyen afirma: "El análisis de la transferencia permite trasformar la repetición en memoria, y así la transferencia pasa, de constituir un obstáculo, a ser el mejor instrumento de la cura" (Etchegoyen, 1997, p. 111) ${ }^{17}$ y así modificar lo perturbador. En el mismo sentido Deserno señala:

El psicoanálisis ha dado cuenta de la reescenificación de patrones de relaciones pasadas y actualmente en el transcurso del tratamiento mediante el concepto de transferencia. Ha ido describiendo paulatinamente los efectos mutuos complejos que consiste, por ejemplo, en que el despliegue de las transferencias depende de una vinculación intensiva al analista y que esa vinculación intensiva es al mismo tiempo la fuerza productiva por el cambio de los patrones de relación inflexible. ${ }^{18}$ (Deserno, 2004, pp. 150151).

Presentadas así las cosas, los estados mentales ni son un fatum ni el superyó cruel es un destino

17. Cabe señalar que Rorty no toma en cuenta a la transferencia cuando describe el objetivo del tratamiento psicoanalítico, pues ve al analista como moderador del debate que presenta un yo con otro yo: uno que cree que su madre es objeto de pena y otro que cree que esa misma madre es una voraz seductora. El analista dejaría que ambas partes expongas sus pros y sus contras. Así, el paciente piensa en términos de conversación (y esto sería una de las razones por lo que el autoanálisis no suele funcionar, por la que el tratamiento puede hacer a menudo lo que no puede hacer la reflexión). "Para los fines del intento consciente del paciente por reconfigurar su carácter, éste no puede utilizar una descripción de sí mismo en términos de catexias, flujo libidinal, etc.: los modelos hidráulicos-topográficos no pueden formar parte de la propia autoimagen, como tampoco una descripción de nuestro sistema endocrino. Cuando el paciente piensa sobre descripciones enfrentadas de sí o de su madre, tiene que pensar dialécticamente, conceder que ambas partes tiene mucho que decir." (Rorty. 1993, p. 211).

18. Heinrich Deserno. Traducción de Marcos Herrera (Comunicación personal). En: Deserno, Heinrich (2004): Psychoanalyse und Psychotherapieforschung - Einleitung. En: Leuzinger-Bohleber, Marianne / Deserno, Heinrich / Hau, Stephan (Eds.): Psychoanalyse als Profession und Wissenschaft. Die psychoanalytische Methode in Zeiten wissenschaftlicher Pluralität. Stuttgart: Kohlhammer, pp. 150151. 
inexorable, el ser humano puede elegir con quiénes relacionarse y desarrollar la capacidad de seleccionar. Lo pensó así Freud en el pasaje subtitulado La división de la personalidad psíquica:

En el curso del desarrollo, el superyó acoge también las influencias de aquellas personas que han ocupado el lugar de los padres, o sea los educadores, los maestros y los modelos ideales. Normalmente, se aleja cada vez más de los primitivos individuos parentales (...). No debemos tampoco olvidar que en edades distintas el niño estima diferentemente a sus padres ${ }^{19}$. (Freud, 1932, Vol III, p. 816).

Hay corrientes psicoanalíticas, no obstante, reticente a la intersubjetividad en el espacio terapéutico. Estos analistas presuponen que son portadores de neutralidad pura o buscan no sugestionar a los pacientes y asumen que pueden dejar de influir sobre sus pacientes o sospechan del poder de un yo hiperconsciente.

Hay quienes sostienen que la cura se obtiene fortaleciendo a ese yo [...). Toda una clínica persigue aliarse con 'las partes sanas del yo' para obtener desde allí una cura mediante la identificación. Así es como la empatía que se promueve esconde mejor la sugestión en que se apoya. Por eso precisamente, otro de los principios de la clínica lacaniana es que nosotros 'renunciamos a todo ideal pedagógico y a todo intento de moldear al paciente a nuestra imagen y semejanza' (Hamann, 2004, pp. 9-11) ${ }^{20}$.
Suponer que en el espacio terapéutico la personalidad del analista no influye en el paciente es como suponer que los consultorios psicoanalíticos son los únicos lugares en los que no rigen tampoco la gravedad ni el tiempo ni otras regularidades de la Tierra. Hay psicoanalistas, además, insertos en lo que Gylbet Ryle ha llamado "la doctrina oficial del dualismo cuerpo-mente", pues mantienen el ideal del retorno a un estado de pureza esencial, y uno llegaría a ser quien realmente es sin la participación de influencia alguna. En el momento en el que lo relacional no importa, podría uno llegar a conocer el reducto mínimo de su ser inalienable ${ }^{21}$. Cuando los psicoanalistas postulan que ellos renuncian a todo ideal pedagógico, a todo intento de moldear al paciente a la imagen y semejanza de ellos, tienen excelentes intenciones, una fina sensibilidad anti-totalitaria y un cuidado atento en no alienar al paciente, pero presuponen que la mente posee una naturaleza no relacional que habría que descubrir. Dicha terapéutica desea remover todas las capturas imaginarias y desea que el analizante se desprenda de sus identificaciones para quedarse con el núcleo duro de su esencia (o el agujero vacío de su anti-esencia). ¿Esto es postular la idea de que existe una causa sui en el sujeto?, y ¿es continuar con la tradición kantiana al creer que existe una instancia limpia de identificaciones e influencias? Desde el panrelacionismo de Rorty (2000, p.170), el psicoanalista no intersubjetivo es la continuación de Platón y la "psicología de las profundidades" tiene un componente esencialista y lleva a plantearse: “"”pero ¿realmente qué soy?, ¿cuál es mi verdadera identidad?, ¿qué me es esencial?"” (Rorty, 1993, p. 205) ${ }^{22}$.

19. Contra la fatalidad que involucraría estar determinado por el padre, también señala Nietzsche la posibilidad de remontar tal situación. "Debido a que los hombres creyeron tener ya la claridad sobre sí mismos, hicieron pocos esfuerzos por adquirirla (...). [Cuando más bien] continúa siendo una tarea completamente nueva (...)”. (Nietzsche. 2007. p. 36).

20. El énfasis es de la autora. Es relevante indicar que para algunos psicoanalistas la cura no es el objetivo principal en el tratamiento sino el autoconocimiento, como discute Graciela Brodsky acerca de la cura como mero pedido de eficacia: "El tema de la eficacia, a pesar de los psicoanalistas está de moda". (Brodsky, 2004). Pero el paciente espera que el tratamiento sea eficaz, al margen de si está de moda o no. De otro lado, cabe indicar que el lacanismo no acepta la utilización del conjunto de emociones del propio analista en la terapia con el paciente porque "sólo designa los efectos de la transferencia que alcanzan al deseo del analista, no como persona, sino en tanto él es puesto en el lugar del Otro por la palabra del analizante, es decir, en una tercera posición que hace la relación analítica irreductible a una relación dual”. (Roudinesco y Plon. 1998, p. 1997).

21. Se mantendría vigente el dualismo entre esencia y accidentes, sustancia y propiedades, realidad y apariencias, naturaleza y convenciones, physis y nomos, cosa en sí y fenómenos, individuum y dividuum.

22. En nota a pie de página dice Rorty: "La gente siempre consideró a los sacerdotes un tanto divertidos, pero también un tanto inspiradores de respeto. Pero los idealistas alemanes y los positivistas anglosajones resultaron meramente divertidos. Por el contrario, la gente se tomó a los psicoanalistas lo suficientemente en serio como para intentar imitarlos, lo que explica la creación del análisis de salón y del psicoblablabla". (Rorty, 1993, p. 205). 
El supuesto socrático de que las conversiones deseables son como un autodescubrimiento más que como una auto-transformación requiere la doctrina platónica de que la mente humana tiene, a grandes trazos, una misma conformación: la dada por el recuerdo de las Formas [puras, no relacionales] (Rorty,1997, p. 67).

La mente, sin embargo, como creación intersubjetiva, como producto relacional, lleva a considerar la terapia de forma activa. El mismísimo Freud señaló que la terapéutica psicoanalítica puede ser resumida en tres fórmulas activas. La primera dice: "transformar en conciente todo lo inconsciente patogénico" (Freud, 1917, Vol II. p. 205), la segunda dice: "llenar todas las lagunas de la memoria de los enfermos, o sea, suprimir sus amnesias" (Freud, 1917, Vol II. p. 205), y la tercera: "robustecer al yo, hacerlo más independiente del superyó, ampliar su campo de percepción y desarrollar su organización, de manera que pueda apropiarse de nuevas partes del ello. Donde era ello, ha de ser yo" (Freud, 1932, p. 824).

Hay otro grupo de psicoanalistas que creen que robustecer al yo no se logra sólo con la comprensión de los patrones antiguos de relación del paciente, sino también en la relación terapéutica en que hay desarrollos emocionales y matices de sentimientos que el paciente aún desconocía. Se trata de incorporar más rasgos de personalidad bajo una rúbrica en constante expansión (Cfr. Nehamas, 2002, p. 220). Rorty está con estos terapeutas, pues la expansión es una forma de eliminar el presupuesto esencialista de excavar y excavar hasta encontrar un núcleo fundamental, y así distingue dos terapias: una busca la pureza y la otra busca la expansión de sí mismo. El deseo de purificación de la vida ascética para llegar al "conócete a ti mismo" fue incitado por Platón y Kierkegaard; en cambio, Nietzsche y Byron propusieron expandirse en una vida estética para llegar al "haz de ti una obra de arte". El deseo de purificarse despojaría de todo lo accidental, mientras el deseo de expandirse a sí mismo es querer abarcar cada vez más posibilidades y arroparse de más accidentes. Al promover un nuevo paradigma psicoanalítico, Juan Pablo Jiménez señala que la principal estrategia de autoexpansión es el enriquecimiento del lenguaje en la medida que permita la mayor interconexión de creencias y muestre las evocaciones y reminiscencias que pueden causar algunas frases significativas en el paciente (Cfr. Rorty, 1993, p. 216).

En psicoanálisis, los dos modelos teóricos y técnicos son el de la pulsión y el del vínculo intersubjetivo. El modelo de la pulsión ve al paciente encapsulado en conflictos intrapsíquicos y su efecto terapéutico (al igual que en el modelo platónico) busca el autoconocimiento. El modelo intersubjetivo suma "la habilidad del terapeuta para remediar carencias del desarrollo. [...] El paciente es visto como habiendo vivido en un mundo cerrado de relaciones de objeto arcaicas que llevaron a profecías autocumplidas" (Jiménez, junio, 2005, p. 73). La relación terapéutica proporciona un correctivo emocional, una relación que permite interpretar las emociones que se producen en el nuevo vínculo.

Para el modelo intersubjetivo -del vínculo, antipulsional y anti-internalista-, Paul-Laurent Assoun yerra al sostener que "el concepto aparece como una máscara de la pulsión" (Asssoun, 1982, p. 96), pues Assoun presupone que el modelo de la pulsión ve más profundamente, basado en una petición de principio o en la "propiedad dormitiva", repitiendo la manera de actuar de la metafísica tradicional.

Lo que la metafísica no pudo hacer, tampoco lo va a hacer la psicología, ni siquiera la psicología muy "profunda": tomamos a Freud por el lado malo si intentamos hallar una formulación [única] de la "motivación moral" que sea algo más que una referencia a las contingencias históricas que configuraron el proceso de acumulación en nuestra región y época. (Rorty, 1993, p. 228).

El modelo del vínculo intersubjetivo parece no perder de vista que es tan sólo una descripción más entre otras y no habría un núcleo irreductible. Tiene la ventaja de facilitar el conocimiento de uno mismo a través de los vínculos que hemos tenido y tenemos con nuestros prójimos. Y respecto del valor práctico y terapéutico, se asume que no hay solipsismo cartesiano y una mente sí afecta negativa o positivamente a otra, y así podemos idear estrategias para fomentar relaciones humanas menos perjudiciales y estrategias para desactivar la influencia de personalidades negativas, 
según lo que nosotros consideremos como positivo y negativo. Ser consciente de los efectos de las relaciones intersubjetivas nos permitirá evaluar el costo-beneficio de nuestras relaciones, y el modelo del vínculo se presenta compatible con el pragmatismo filosófico, pues ve como irrelevante la preocupación ontoteológica por lograr poseer la respuesta a la pregunta ¿quién soy en realidad? Rorty sugiere comprender las identidades de acuerdo no con descripciones representacionalistas y logocéntricas, sino bajo el carácter relativo de la identidad con respecto a la elección de distintas descripciones. Ya no se pregunta por cuál es la descripción que se adecua correctamente a la esencia de la realidad tal como ella es en sí misma, se pregunta por cuáles son las descripciones que pueden generar mejores consecuencias para determinados fines. Mientras alguna gente pase su vida preguntando “¿quién soy realmente?”, nosotros podemos avanzar en lo terapéutico y "desarrollar una técnica con intervenciones terapéuticas específicas, activa, focal, flexible (...) y que junto al papel fundamental de hacer consciente lo inconsciente, enfatice la importancia de la memoria procesal, de la reestructuración cognitiva, del cambio en la acción y la exposición a nuevas experiencias". (Jiménez, 2005, p. 86).

Elaborar los estados mentales por uno mismo no significa que uno los prepara aisladamente, sino que los tramita por medio del diálogo, en parte abierto, en parte incorporado con otras personas, y, así, la propia identidad depende de modo crucial de la relación dialógica con otros. El filósofo Charles Taylor indica que "si algunas de las cosas a las que doy más valor me son accesibles sólo con relación a la persona que amo, entonces esa persona se convierte en algo interior a mi identidad" (Taylor, 1991, p. 70); en tal sentido "definirme significa encontrar lo que resulta significativo en mi diferencia con respecto a los demás" (Taylor, 1991, p. 71). Incluso el eremita y el artista solitario aspiran al carácter dialógico, sea con Dios o con un público futuro. No reconocer lo vital del diálogo para la creación continua de nuestra mente es propio de una cultura egocéntrica y narcisista negativamente, que lejos de crecer queda atrofiada al haberse sobrestimado como núcleo y esencia invariable y no necesitar del otro como referente. Freud mismo reconoció el papel que juega el otro en la identidad del sujeto al rechazar la oposición clásica entre psicología individual y psicología de las masas:
En la vida anímica individual aparece integrado [...] 'el otro', como modelo, objeto, auxiliar o adversario, y de este modo, la psicología individual es al mismo tiempo y desde un principio psicología social [...]. Las relaciones del individuo con sus padres y hermanos, con la persona objeto de su amor y con su médico, esto es, todas aquellas que hasta ahora han sido objeto de la investigación psicoanalítica, pueden aspirar a ser consideradas como fenómenos sociales. (Freud, 1921, Vol III, p. 1141).

Si en la vida anímica individual aparece integrado el otro, para comprender lo mental, se puede postular que lo mental de cada persona es tanto el recipiente en el que se vierten las experiencias sociales como el fluido que llega a los otros. El punto es que "no entendemos mejor la naturaleza de lo mental mirando hacia adentro, como en la concepción cartesiana, sino observando las interacciones sociales". (Quintanilla. 2003, p. 6).

\section{ADENDA}

[1] No obstante lo argumentado sobre la novedad de la perspectiva freudiana, consideremos también la aguda observación del escritor Giovanni Papini acerca del padre del psicoanálisis. En el Gog, el escritor italiano inventa una entrevista en que Freud revela, a manera de confesión, las secretas deudas literarias del psicoanálisis.

Fui y soy un poeta y novelista bajo la figura de hombre de ciencia. El psicoanálisis no es otra cosa que la transformación de una vocación literaria en términos de psicología y de patología. El primer impulso para el descubrimiento de mi método nace (...) de mi amado Goethe. Usted sabe que escribió el Werther para librarse del íncubo morboso de un dolor: la literatura era para él catarsis. ¿Y en qué consiste mi método para la curación del histerismo sino en hacérselo contar todo al paciente para librarle de la obsesión? No hice nada más que obligar a mis enfermos a proceder como Goethe. La confesión es liberación, esto es, curación. Lo sabían desde hace siglos los católicos, pero Víctor Hugo me había enseñado que el poeta es también sacerdote, y así substituí osadamente al confesor. 
El primer paso estada dado. Me di cuenta bien pronto de que las confesiones de mis enfermos constituían un precioso repertorio de documentos humanos. Yo hacía, por tanto, un trabajo idéntico al de Zola. Él sacaba, de aquellos documentos, novelas; yo me veía obligado a guardarlos para mí. La poesía decadente llamó entonces mi atención sobre la semejanza entre el sueño y la obra de arte y sobre la importancia del lenguaje simbólico. El psicoanálisis había nacido (...) de la transposición científica de las Escuelas literarias amadas por mí. El Romanticismo que (...) había proclamado la primacía de la pasión y reducido toda pasión al amor, me sugirió el concepto del sensualismo como centro de la vida humana. Bajo la influencia de los novelitas naturalistas, yo di del amor una interpretación menos sentimental y mística, pero el principio era aquél. El Naturalismo, y sobre todo Zola, me acostumbró a ver los lados más repugnantes, pero más comunes y generales, de la vida humana; la sensualidad y la avidez bajo la hipocresía de las bellas maneras; en suma, la bestia en el hombre. Y mis descubrimientos de los vergonzosos secretos que oculta el subconsciente no son nada más que una nueva prueba del despreocupado acto de acusación de Zola. El Simbolismo, finalmente, me enseño dos cosas: el valor de los sueños, asimilados a la obra poética, y el lugar que ocupan el símbolo y la alusión en el arte, esto es, en el sueño manifiesto. Entonces fue cuando emprendí mi gran libro sobre la interpretación de los sueños como reveladores del subconsciente (...). Para completar el cuadro de mis fuentes literarias, añadiré que los estudios clásicos (...) me sugirieron los mitos de Edipo y de Narciso; me enseñaron, con Platón, que el estro, es decir, el surgir del inconsciente, es el fundamento de la vida espiritual $\mathrm{y}$, finalmente, con Artemidoro, que toda fantasía nocturna tiene su recóndito significado. (...) La forma de mi espíritu se halla inclinada al ensayo, a la paradoja, al dramatismo (...). Hay una prueba irrefutable: en todos los países en donde ha penetrado el psicoanálisis ha sido mejor entendido y aplicado por los escritores y por los artistas que por los médicos. Mis libros, por otra parte, se asemejan mucho más a obras de imaginación que a los tratados de patología. Mis estudios sobre la vida cotidiana y sobre los movimientos del espíritu son verdadera y genuina literatura, y en Tótem y tabú me he ejercitado incluso en la novela histórica. (Papini, 1957, pp. 136-138)

\section{REFERENCIAS}

Assoun, Paul-Laurent (1982). Freud. La filosofía y los filósofos. Traducción de Alberto Luís Bixio. Buenos Aires: Paidós.

[Biblia] Biblia de Jerusalén (1998). Edición española dirigida por José Ángel Ubieta. Bilbao: Desclée de Brouwer.

Brodsky, Graciela. Seminário Internacional dictado durante el XIV Encontro Brasileiro do Campo Freudiano: Fazer análise. Porque, quando e como. Rio de Janeiro, 23 y 24 de abril de 2004. Publicado en: Opção Lacaniana, Revista Brasileira Internacional de Psicanálise, $\mathrm{N}^{\circ}$ 41, Sao Paulo, diciembre de 2004. Texto establecido por: Elisa Monteiro y Heloisa Caldas.

Cavell, Marcia (2000). La mente psicoanalítica. De Freud a la filosofía. Traducción de Gabriela Montes de Oca. México D.F.: Paidós.

Davidson, Donald (1982). "Paradoxes of irrationality". en: R. Wollheim y J. Hopkins (comps.), Philosophical Essays on Freud, Nueva York/ Cambridge: Cambridge University Press.

Deserno, Heinrich (2004). Traducción de Marcos Herrera (Comunicación personal). En: Deserno, Heinrich : Psychoanalyse und Psychotherapieforschung - Einleitung. En: Leuzinger-Bohleber,Marianne/Deserno,Heinrich /Hau,Stephan (Eds.): Psychoanalyseals Profession und Wissenschaft. Die psychoanalytische Methode in Zeiten wissenschaftlicher Pluralität. Stuttgart: Kohlhammer.

Etchegoyen, Horacio (1997). Los fundamentos de la técnica psicoanalítica. Buenos Aires: Amorrortu.

Freud, Sigmund (1948). Obras completas. Traducción de Luis López-Ballesteros y de Torres. Madrid: Editorial Biblioteca Nueva, VOL. III.

1895 "Estudios sobre la Histeria".

1913 "Múltiple interés del psicoanálisis". 
1914 "Introducción al psicoanálisis".

1915 "Lo inconsciente".

1917 "Introducción al psicoanálisis".

1921 "Psicología de las masas".

1923 "El yo y el ello".

1930 "El malestar en la cultura".

1932 "Nuevas conferencia de introducción al psicoanálisis".

Green,André. "La representación y lo irrepresentable." En: Revista de Psicoanálisis. APA. Número especial Internacional, 1998-1999: 6.

Hamann, Marita (2004). Jaques Lacan. El nacimiento de una escuela. Lima: Benvenuto Editores.

Jiménez, Juan Pablo (2005). “Después del pluralismo: hacia un nuevo paradigma psicoanalítico integrado", En: Revista de psicoanálisis. Lima: NO 4 (junio).

Kernberg, Otto (1994). La agresión en las perversiones y en los desórdenes de la personalidad. Traducción de Jorge Piatigorsky. Buenos Aires: Paidós.

Nehamas, Alexander (2002). Nietzsche. La vida como literatura. Madrid: Fondo de Cultura Económica.

Nietzsche, Friedrich (2001). Así habló Zaratustra. Traducción de J. Leyva. Madrid: Alba.

Nietzsche, Friedrich (2007). La ciencia jovial. Traducción de Alicia Varela. Buenos Aires: GRADIFCO

Papini, Giovanni. (1957). Gog. Traducción de Mario Verdaguer. Barcelona: AHR.

Platón (1970). Fedro. Traducción de Luís Gil, Madrid: Instituto de Estudios Políticos.

Quine, Willard Van Orman (1969). Los métodos de la lógica. Traducción de M. Sacristán Luzón. Barcelona: Ariel, [1962]

Quintanilla, Pablo (2003). "El lenguaje de la intimidad: sobre la constitución intersubjetiva de las emociones." En: Holguín, Hoyos. Del espejo a las herramientas. Bogotá: Universidad Nacional de Colombia.

Fecha de recepción: 6 de febrero de 2016

Fecha de aceptación: 30 de marzo de 2016
Rey de Castro, Álvaro (1995). "El texto inaugural del psicoanálisis: a cien años de Estudios sobre la Histeria”, en: Cuadernos de la Facultad de Letras y Ciencias Humanas. Lima: Pontificia Universidad Católica del Perú. Marzo. N0 12. (Marzo).

Rorty, Richard (1993). Ensayos sobre Heidegger $y$ otros pensadores contemporáneos. Escritos filosóficos 2. Traducción de Jorge Vigil Rubio. Barcelona: Paidós.

Rorty, Richard (2000). El pragmatismo, una versión. Antiautoritarismo en epistemología y ética. Traducción de Joan Vergés G. Barcelona: Ariel.

Rorty, Richard (1997). ¿Esperanza o conocimiento? Una introducción al pragmatismo. Traducción de Enrique Rabossi. Buenos Aires: F.C.E.

Roudinesco, Elizabeth y Michel PLON (1998). Diccionario de psicoanálisis. Buenos Aires: Paidós.

Russell, Bertrand (1983). La perspectiva científica. Traducción de G. Sans Huelin. Madrid: Sarpe.

Ryle, Gilbert (1967). El concepto de lo mental. Traducción de Eduardo Rabossi. Buenos Aires: Paidós.

Stern, Daniel (1987). The Interpersonal World of the infant. Nueva York: Basic Books.

Taylor, Charles (1991). La ética de la autenticidad. Traducción de Pablo Carbajosa Pérez. Barcelona: Paidós.

Vargas Llosa, Mario (2010). Conversación en la Catedral. [1969]. Lima: Alfaguara.

Vattimo, Gianni (2004). Introducción a Nietzsche. Traducción de Jorge Binaghi. Barcelona: Península.

Wittgenstein, Ludwing (1992). Lecciones y conversaciones sobre estética, psicología y creencia religiosa. Traducción de Isidoro Reguera. Barcelona: Paidós. 